\title{
LAS COMUNIDADES MAPUCHE Y EL RUCAPILLÁN, UNA RELACIÓN DE RECIPROCIDAD
}

The mapuche communities and the Rucapillán, a relationship of reciprocity

\author{
Maritza Marín-Herrera \\ Universidad de Costa Rica, Costa Rica \\ mmarin72@gmail.com
}

Recibido: $16-01-2018$

Aprobado: 30-04-2018

\section{RESUMEN}

Maritza Marín Herrera es Este artículo expone algunas formas de relacionamiento entre las Licenciada en Sociología por la Universidad de Costa Rica y Magíster en Desarrollo a Escala Humana y Economía Ecológica por la Universidad Austral de Chile. Se desempeña como docente de la Escuela de Estudios Generales de la Universidad de Costa Rica. comunidades mapuche colindantes con el Parque Nacional Villarrica y su territorio ancestral, para reconocer las transformaciones y adaptaciones en sus modos de vida, suscitados por el establecimiento del Parque en 1940. La voz de las personas que han vivenciado procesos de alejamiento a la naturaleza presente en ese territorio ancestral, se encuentra a través de este trabajo etnográfico. Se concluye que las comunidades han experimentado cambios y adaptaciones de sus prácticas culturales, acompañadas de una fuerte resistencia y lucha constante por recuperar el territorio frente al Estado chileno. Igualmente han conservado una relación de reciprocidad con la naturaleza propia de su cosmovisión pese a las limitaciones de acceso a los recursos.

Palabras clave: comunidades mapuche; Parque Nacional Villarica; cosmovisión mapuche

\begin{abstract}
This article exposes some forms of relationship between the mapuche communities adjoining the Villarrica National Park and their ancestral territory, to recognize the transformations and adaptations in their ways of life, brought about by the establishment of the Park in 1940. The voice of the people who have experienced processes of distance to the nature in that ancestral territory, is found through this ethnographic work. It is concluded that the communities have experienced changes and adaptations of their cultural practices, accompanied by a strong resistance and constant struggle to recover the territory against the Chilean State. They have also maintained a relationship of reciprocity with the nature of their worldview despite the limitations of access to resources.
\end{abstract}

Keywords: mapuche communities; Villarica National Park; mapuche worldview 


\section{Introducción}

La creación del Parque Nacional Villarrica, Chile, en 1940, mediante decreto No. 2236, del Ministerio de Tierras y Colonización, es uno más de los hechos de despojo territorial que experimentan las comunidades mapuche del sur de Chile. El destino dado a las 63.000 hectáreas que lo conforman, es quizá una de las razones por las cuales los reclamos territoriales son invisibilizados, ya que la conservación es un tema de relativo consenso entre el saber/poder científicopolítico y los intereses de resguardo de las comunidades mapuche, aunque esto implica evadir la conflictividad presente en el lugar.

Visibilizar el tipo de relación que establecen los diferentes actores involucrados con el territorio mapuche, en los alrededores del Volcán Villarrica, es fundamental para reconocer las transformaciones y adaptaciones en sus modos de vida,

Para la CONAF (Corporación Nacional Forestal), el Parque Nacional Villarrica es un área cuyo objetivo es la preservación de ambientes naturales, disponibles sólo para la educación, investigación y recreación, siempre y cuando no afecten dicho objetivo; para el pueblo mapuche ese espacio consiste en una parte de su Mapu ${ }^{1}$, debe resguardarse, es decir, usado con respeto y cuidado, un uso basado en la espiritualidad. En el fondo de estas concepciones, se encuentran dos formas de relacionarse con la naturaleza, con la alteridad. Esta dicotomía ontológica, se traduce en disputas entre dos entes sociales: la institucionalidad chilena -representada en la CONAF, Bienes Nacionales, Municipalidad y otras entidades- y las comunidades mapuche aledañas al parque; pero también intervienen actores sociales privados y organismos no gubernamentales, todos con intereses diversos.

Este artículo centra su atención en la visión mapuche del territorio, para comprender su significado y las consecuencias de su despojo. Se caracterizan y analizan, la relaciones con la naturaleza, desde la voz de los actores sociales que lo vivencian.

El trabajo aborda las comunidades mapuche que colindan al sur de las fronteras del Parque Nacional Villarrica, específicamente las establecidas mediante Títulos

\footnotetext{
1 "La idea de espacio o mapu en el conocimiento mapuche, se encuentra asociada a diversas dimensiones, tanto materiales o intangibles, como espirituales o trascendentales" (Millalén Paillal, 2006).
} 
de Merced², otorgados en los años 1912-1913 por el Estado Chileno (Aylwin, 2008) estas son: Ramón Chincolef, Juan Chañapi, Juan Caripán, Carlos Antimilla, todas en la comuna de Panguipulli, Región de los Ríos.

\section{La relación de las comunidades mapuche con la naturaleza}

El Parque Nacional Villarrica según el Plan de manejo (Corporación Nacional Forestal, 2006, 2013), tal como se observa en la llustración № 1, es una ramificación lateral de este a oeste de la Cordillera Andina, que comprende del Volcán Lanín (a la derecha abajo) en el límite con Argentina, los faldeos del Volcán Quinquilil, los faldeos del Volcán Quetrupillán y los faldeos del Volcán Villarrica (arriba a la izquierda). Los volcanes son elementos imponentes en el territorio y por tanto los referentes para establecer sus límites.

Ilustración № 1. Foto Satelital Parque Nacional Villarrica.

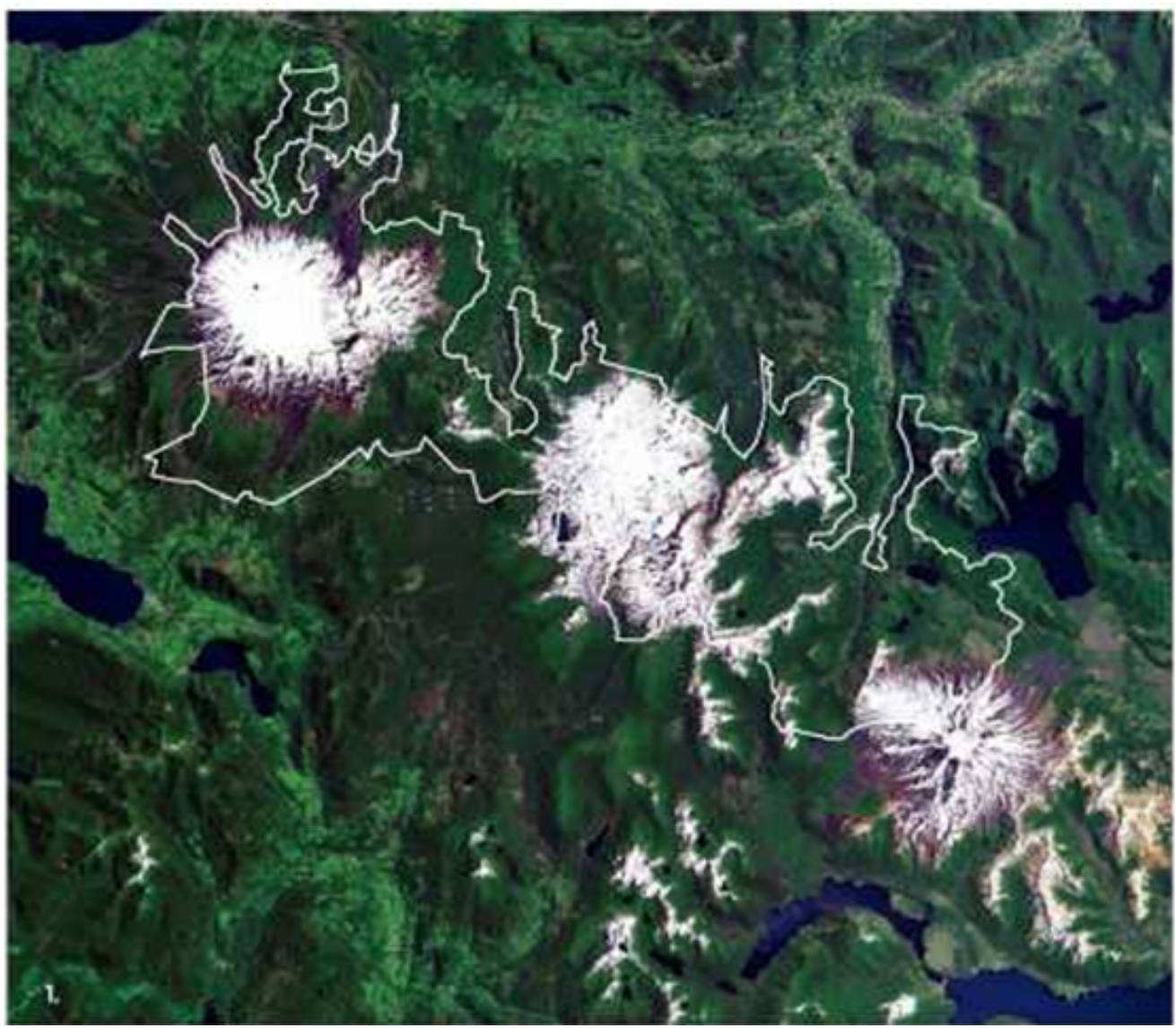

\footnotetext{
${ }^{2}$ Mediante Ley de 1866, fueron otorgados "Títulos de Merced" con los cuales se ordena, deslindar y levantar planos de los terrenos y las posesiones indígenas para ser titulados a los adjudicatarios una vez que prueben la "Ocupación efectiva y continuada por un año"; esa ocupación incluye solamente "la ruca, los huertos familiares y lo cercado, dejando fuera del dominio mapuche los territorios de pastoreo, ramoneo, extracción de leña y de recolección de frutos, es decir, la ocupación antigua, aquella que permitía la supervivencia material y cultural de las familias mapuche" (Correa \& Mella, 2010).
} 
Para las poblaciones que nos ocupan, el "Rucapillán"3 (nombre originario del Volcán Villarrica), es de gran relevancia, constituye un elemento consustancial a la cosmovisión mapuche. Según una lideresa mapuche "para las comunidades que están cercanas al volcán, el volcán tiene un rol fundamental, pero para los que estamos más lejos también tiene un significado" (B.C., comunicación personal, 23 de abril de 2015). En el mismo sentido, señala otra lideresa de la comunidad Carlos Antimilla, "es una necesidad para las comunidades tener volcán, porque desde ahí baja el newen ${ }^{4 "}$ (B.H., comunicación personal, 6 de setiembre de 2015).

El sentido que se le otorga deja entrever la relación continuada entre lo humano y no humano presente en la cosmovisión mapuche. Muchas de las historias significativas en el territorio se relacionan con lo no humano como ente vivo, interactuante y con incidencia en la acción y destino de los seres humanos.

Es así como el Rucapillán tiene historias que se entremezclan con los eventos cotidianos y los extraordinarios, de gentes cuya vida está marcada por su newen y con su presencia paisajística cruzando sus subjetividades. Algunas de estas historias, contadas por personas mayores de cincuenta años, que han sido transmitidas oralmente por los antecesores, ilustran las relaciones intranaturaleza y naturaleza-ser humano. Se relata, por ejemplo, que el MochoChoshuenco era un volcán malo, traía muchas enfermedades, plagas, se cuenta que un día vieron a un ternero bajar del volcán con sangre en su nariz y, desde ese día, muchas personas tuvieron el mismo sangrado por la nariz hasta que morían. Los antepasados rogaron porque terminaran aquellos males enviados por el Mocho-Choshuenco; hasta que un día, los espíritus de cada volcán, el Mocho-Choshuenco y el Villarrica se enfrentaron. Y el Villarrica, que es un volcán bueno, tiró un rayo y cortó el cráter del Mocho-Choshuenco, desde entonces, este último no tiene actividad (Notas de campo, 23 de abril de 2015).

En este relato se identifica la capacidad de la naturaleza para intervenir en la vida de las personas, y la relación que éstas establecen con la primera, pues se le ruega y la naturaleza responde, protege, cuida, como acto recíproco a la rogativa. También está presente la idea del bien y el mal, y la representación de estos en elementos no humanos -un volcán bueno y otro malo-. Se reitera, por los vecinos, que el Rucapillán tiene un espíritu bueno, que les protege y no les

\footnotetext{
${ }^{3}$ Rukapillán: en mapuzungún se refiere a la morada de los espíritus.

${ }^{4}$ Newen: en mapuzungun se refiere a la fuerza, energía.
} 
dañaría con una erupción, es por eso que les avisa con tiempo si va a tener actividad fuerte, para que las personas se preparen.

...yo por el puro conocimiento de los abuelos me quedé y funcionó lo que los abuelos me dijeron... Desde el principio, yo dije no va haber corrida, no va haber corrida, incluso se lo dije a las autoridades, esos son conocimientos ancestrales...5 (J.C., comunicación personal, 6 de setiembre de 2015).

Esta convicción, acerca de la comunicación entre la naturaleza y el ser humano, persiste frente a una serie de historias de duelo que muchos de los habitantes comparten, al haber perdido familiares cercanos en la erupción del año 1971 y que se reactiva cada vez que inicia actividad volcánica. La última erupción del 3 de marzo de 2015, aviva los sentimientos de duelo por los seres perdidos, pero también la seguridad en los espíritus que habitan el volcán y su bondad. Uno de los recuerdos más persistentes corresponde a los relacionados con el escorial (ver llustración $N^{\circ} 2$ ), pues afirman diferentes vecinos que ese material lo vieron bajar como agua cristalina en la última erupción fuerte, antes de enfriarse y convertirse en roca.

Ilustración № 2. Fotografías del Escorial, camino de lava hecho por la erupción del Volcán Villarrica en 1971.

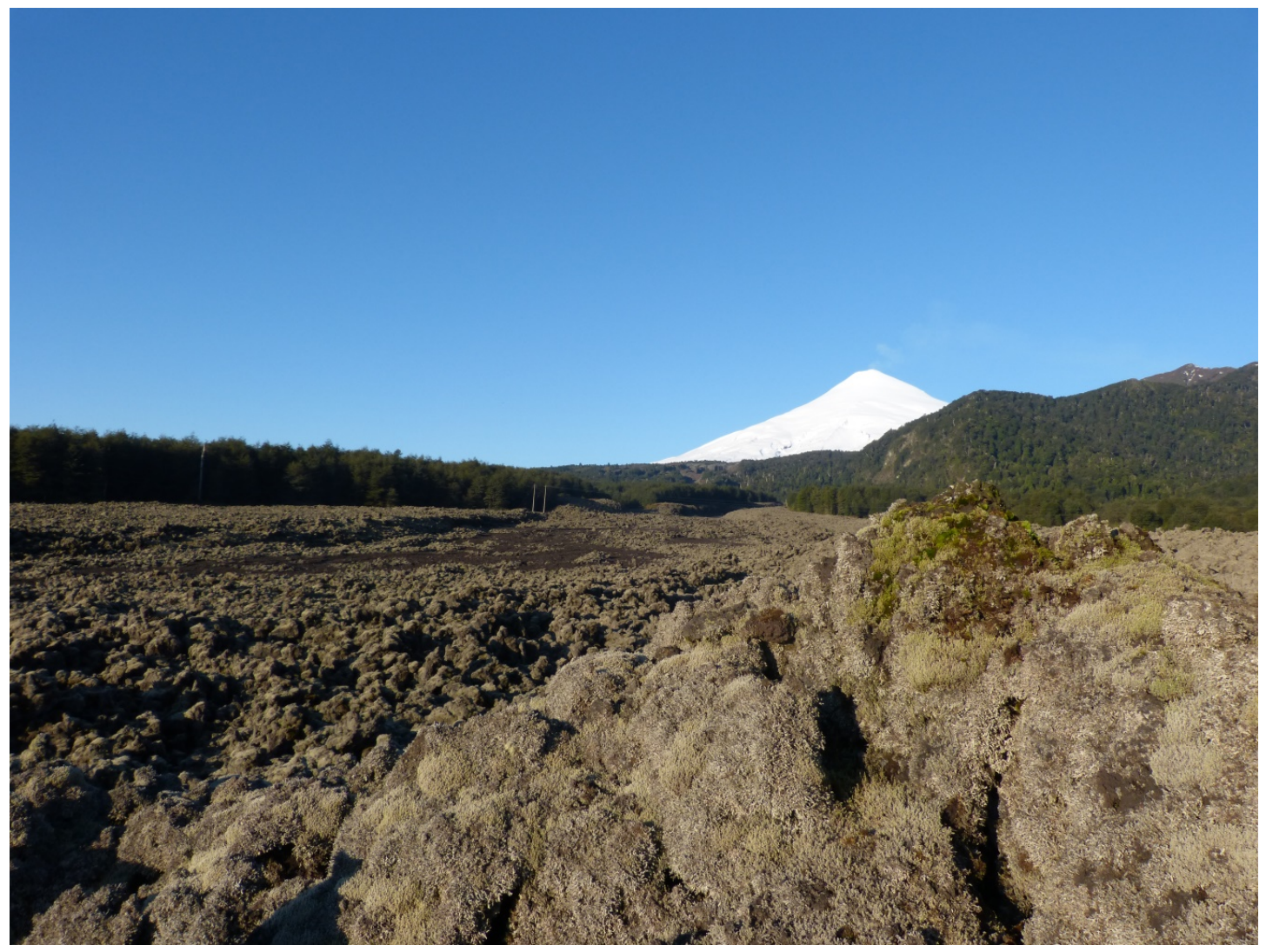

${ }^{5}$ Se refiere a la actividad volcánica iniciada por el Rucapillán el 3 de marzo de 2015. 


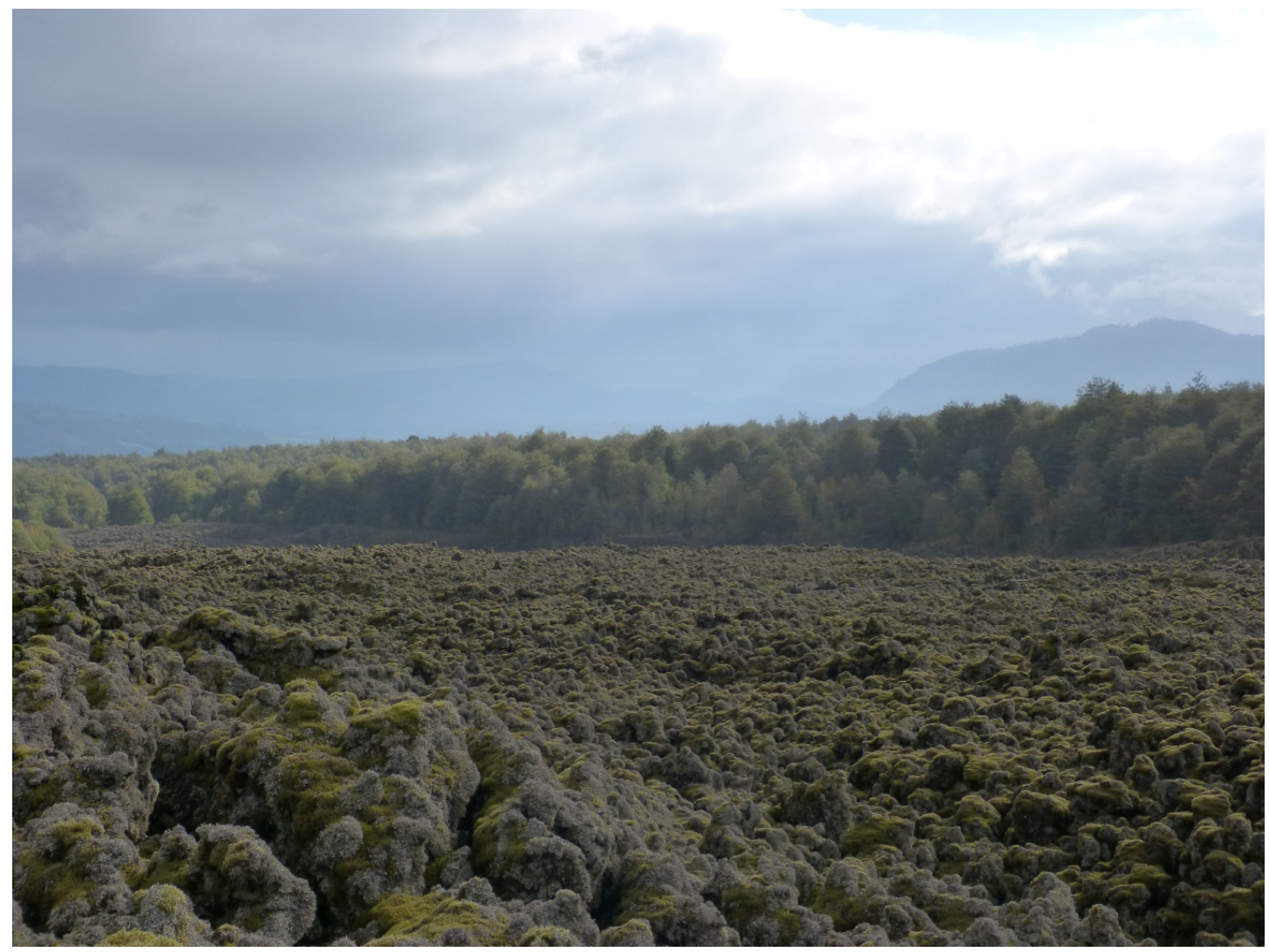

Además de ser bueno, porque avisa con tiempo antes de una erupción, algunos le atribuyen al Rucapillán un espíritu femenino, cuentan una historia que igualmente conjuga entes de diversas naturalezas. Se trata de una niña virgen que se va a casar con su amado, esta niña es de Challupén. Pero antes de la boda, tiene un sueño que le dice que debe sacrificarse, pidiendo a su amado que le saque el corazón y lo lance al volcán. Su amado, a pesar de no querer ejecutarlo, termina aceptando su destino y, luego de hacerle una cama de flores donde se posa la niña virgen, le saca el corazón y lo levanta con su mano, este es arrebatado por un pájaro que lo lleva y lo lanza al volcán. Mientras el corazón es trasladado, las gotas de sangre que caían se iban convirtiendo en flores de copihue. Por eso es que, sólo en el sur de Chile, se encuentra este tipo de flor, según dicen. El sufrimiento de aquel hombre fue tanto que acabó con su vida (A.M., notas de campo, 23 de abril de 2015). En este relato se incorporan más elementos, pues el volcán interviene en las relaciones entre humanos y no humanos, hace posible la creación de nuevos elementos de la naturaleza y hace confluir la muerte y la vida. 
Estas historias no son únicas, según dice una líder de la comunidad Carlos Antimilla, el Rucapillán tiene tanto espíritu femenino como masculino, y cada territorio y comunidad ancestral tienen sus propias historias, y su forma de relacionarse con él. Por eso, cada comunidad sabe hasta dónde llega su territorio, no se trata sólo de los límites establecidos por los Títulos de Merced, por las fronteras del Parque Nacional o los señalamientos que haga cualquier tipo de división territorial. El volcán es un referente geográfico para separar territorios o determinar fronteras ancestrales -la punta del volcán se señala como el límite adonde llegan los derechos mapuche, en conjunto con otro elemento de la naturaleza, que es el Lago Calafquen- existen elementos culturales que definen también los límites entre las comunidades:

El tema es que los mapuche también tenían reglamentos aunque no escrito, era global y cada uno sabía dónde... todas las comunidades tienen esa cosa, ellos por donde piden y por donde baja el newen, cada uno sabe, y eso saben clarito por donde bajaba la ayuda (B.H., comunicación personal, 6 de setiembre de 2015).

Es decir, si cada comunidad tiene relación de manera diferenciada con el territorio, se pueden reconocer diferentes modos de vida entre las diferentes comunidades mapuche. Lo que sí es común a todas las comunidades es la concepción del volcán como ente vivo. El volcán se reconoce como un hermano, un ser sagrado al que se le respeta y se le pide, de esta relación surgen una serie de prácticas ceremoniales, cuyas dinámicas son interrumpidas por la intervención del territorio como espacio para la conservación.

... porque esa tierra, lo que es Pillán en el Guillatún nosotros todos lo adoramos, lo guillatukamos, porque es nuestro, entonces si llegara otro particular, vamos a estar guillatucando lo que no es nuestro...(Ñ.W., comunicación personal, 12 de mayo de 2015).

El guillatún consiste en una ceremonia donde se hace la rogativa a Gnechén para que todo el territorio esté bien, está a cargo de un lonko o líder de la comunidad reconocido como tal, según dicen, el lonko

tiene que subir más arriba, donde Gnechén, a decirle, pedirle que nos dé buena vida, que nos ayude, todas esas cosas, como el winca hace en sus ceremonias [...] el lonco tiene que orar por su pillán, por su mapu también, también por su lawen ${ }^{6} .$. (Ñ.W., comunicación personal, 12 de mayo de 2015).

Durante la ceremonia, se lleva una pipa de palo: "con eso ppu [hace sonido de botar humo por la boca] igual que el pillán, eso significa que uno hace lo mismo

\footnotetext{
${ }^{6}$ Lawen es remedio o medicina en mapuzungún.
} 
que él hace y somos hermanos, soy tu hijo, soy tu hermano, yo hago lo mismo que tú" (Ñ.W., comunicación personal, 12 de mayo de 2015); es decir, hay una hermandad con el pillán que lo convierte en un par, un igual que debe ser respetado, con quien se entra en diálogo, pero que no es sujeto de dominio, no es un objeto al que se le extraen "bienes y servicios".

Las personas en las comunidades tienen clara la sabiduría de su pueblo, en relación con la naturaleza, de ahí que no sólo el volcán es digno de respeto sino, también los otros cerros y elementos presentes en el territorio. En cada nivel del territorio se encuentran diferentes relaciones de colaboración entre ser humano y naturaleza.

...después viene bajando la ceremonia así como vamos llegamos al pillán, que es nuestro, y nuestra ceremonia va bajando al cerro más chico, conün huinkul le decimos al pillán, después viene el Milimili, que tiene lawen, que nos protege, después bajamos más abajo que vivimos aquí, y el lado donde nosotros nos protegemos, nos bañamos también de repente también hay lawen en el lago, tiene remedio, medicina, dentro de su lafken (Ñ.W., comunicación personal, 12 de mayo de 2015).

Se denotan relaciones diferenciales con el territorio, de acuerdo con las características del elemento presente; con cada uno establecen intercambios diferentes, por tanto, las rogativas se adaptan también a las necesidades de los actores intervinientes. La naturaleza no se jerarquiza, sino que se reconoce su aporte diferencial a la vida material y espiritual del mapu, porque hay una vinculación con todos los componentes del territorio.

\section{Los faldeos del Rucapillán: alimento y medicina para el cuerpo y el espíritu}

En los faldeos del Rucapillán, se hace referencia a la existencia de lawen y de alimento, no sólo para el sustento material sino también espiritual: "...un viaje, por ejemplo, a lo que es las cercanías del volcán, también era una especie de retiro, aparte de buscar piñón, de buscar algún producto era una especie de retiro espiritual, se recargaba como energía..." (B.C., comunicación personal, 23 de abril de 2015).

Lo material y espiritual nunca es separado, de ahí que la recolección del piñón o piñonada, práctica cultural de gran relevancia para las comunidades aledañas al parque, siempre va acompañada de una ceremonia donde se le ruega a Gnechén para que la producción de piñón sea abundante, pero eso implica 
también pagar o devolver algo a la naturaleza. De esta manera, se cuenta de una primera araucaria, que se encuentra en la entrada del bosque, donde se hacía la rogativa y se pasaba a dejar algo de lo recolectado:

...un pino sagrado, muy sagrado para nosotros, el primero, luego empezaron a correrle hacha y está todo así punteado con hacha, y ya nosotros pasamos a pedirle yo cuando voy a escondidas a piñonear y paso a pedirle e igual le paso a dejar algo y de ahí me paso a despedirme y me vengo... (A.M., comunicación personal, 9 de mayo de 2015).

En la actualidad, es recurrente la queja de que no se puede recolectar piñón todos los años, cada vez es más espaciado el tiempo de cosecha. Algunas de las explicaciones a este fenómeno giran en torno a la desvinculación con las prácticas ancestrales, entre ellas, la rogativa, la devolución o pago por los favores de la naturaleza, pero también hace relación con las formas de recolección.

Antes a Gnechén le pedía para que haiga frutos, ahora ni siquiera hay piñones, ahora ya no están dando, antes por medio de una ceremonia pidiéndole a la naturaleza había cierta producción de piñones, porque había gente que sabía pedirle a la naturaleza... (A.M., comunicación personal, 9 de mayo de 2015).

Esta es una de las prácticas más afectadas con la constitución del Parque Nacional Villarrica, que si bien sigue realizándose, pierde mucho de su contenido. Según señala un adulto mayor de la comunidad Juan Chañapi, sobre el establecimiento del parque:

Fue una forma más de que a los Mapuches se les quitara tierra, el título de merced ya había quitado tierra, y ahora el decreto 2568 divide a las comunidades establecidas en el título merced, y de cortina entre estas tierras y el volcán se produce un parque hoy día conocido como Parque Nacional Villarrica, ¿qué pasa ahí? Se nos vulnera el derecho que teníamos para con eso, porque eran tierras indígenas y hoy día no se puede ingresar ahí... (E.H., comunicación personal, 28 de junio de 2015).

Se evidencia la percepción de despojo, donde sobresale lo inmaterial como relevante ante un otro, el Estado que los despoja. Los miembros de las comunidades hacen referencia a sus derechos como personas originarias del lugar, a establecer una relación con la naturaleza propia de su cosmovisión. Cuando se establece una frontera o una "cortina" entre el volcán y las tierras reducidas, se limita la relación con el entorno natural, y sus significados, incluido el pewen. 
En el recuerdo de los mayores se mantienen detalles del piñoneo, que deja claro que esta no es una actividad meramente productiva, "sino una práctica familiar, dirigida por las personas más antiguas y/o líderes del territorio. En ella se genera un intercambio social, toda vez que durante un mismo período de tiempo se daban el encuentro familias provenientes de distintos lof" (Roma, 2012) bajo las Araucarias. Según señalan los vecinos, además, es una práctica colaborativa:

...ellos iban a estar ahí 15 días, un mes, cada vez que iban, porque si había que construir un techo ellos lo hacían con hacha, usando la misma madera que había ahí y construían el techo, y después otro grupo hacía lo otro, por ejemplo, hacer las paredes, así trabajaban, sin siquiera no se conocían pero ya cuando veían algo con techo, alguien empezaba a cerrar por los lados, era como el patrimonio de todos, no era de alguien en particular (E.H., comunicación personal, 28 de junio de 2015).

Algunas de las personas que se refieren a la piñonada, lo hacen desde el recuerdo, y las narraciones de sus padres y abuelos, no desde la práctica propia de la actividad, precisamente por el obstáculo que significa la apropiación estatal del territorio; por lo tanto, la transmisión oral de la experiencia es fundamental para mantenerla como una práctica identitaria de los pewenches:

...mi mamá vivió eso, ellos iban a quedarse allá, por ejemplo hasta terminar un techo, y no eran nada dos metros, varios metros, cosa que si llegaban dos o tres familias, perfectamente podían compartir ahí el techo (E.H., comunicación personal, 28 de junio de 2015).

Yo nunca fui, porque Yo me quedaba en la casa cuidando los animalitos, y los otros eran hombres, pero tenía que quedarse alguien en la ruka... (M.M., comunicación personal, 6 de setiembre de 2015).

Sin embargo, para quienes sí participaron de la piñonada, cuando las restricciones eran menores que en la actualidad, en su recuerdo está presente, no sólo la actividad de recolección, sino la convivencia con sus pares, los sabores generados por el uso del alimento sagrado y los valores de reciprocidad entre humanos y entre humanos con la naturaleza, mediante la convivencia y la rogativa.

Todos los años íbamos, incluso habían familias, personas que iban hasta dos veces al año, incluso allá tenían los utensilios más pesados, la piedra para hacer el catuto de piñón, echaban a cocer el piñón, hacían catuto y con eso tenían la chunca que se dice, lo tenían allá de todo así bien protegido. (H.H., comunicación personal, 28 de junio de 2015).

Así como el piñón, aunque con significado menos sagrado, hay otras plantas presentes en las faldas del Rucapillán que forman parte de la cultura culinaria de 
las comunidades mapuche, entre los más mencionados se encuentran diferentes tipos de hongos y frutos silvestres:

...aparte del piñón, de la madera para leña para construcción, están las variedades de hongos, frutos silvestres también, hay harto potencial económico que permitiría tener una mejor alimentación, o más variada (B.C., comunicación personal, 23 de abril de 2015).

Uno de los hongos relevantes, mencionados por los vecinos del Parque, es la "lengua de vaca", la cual se caracteriza según sigue:

...es igual que la carne, coloradito, nace de un palo muerto en los troncos y uno la saca de ahí, se encuentra en la montaña gruesa, en el Parque Nacional Villarrica en este tiempo se encontraría. (A.M., comunicación personal, 9 de mayo de 2015).

Pero también se ubica lawen que no se encuentran a otras alturas del territorio.

...ahí se dan otras plantas que aquí no se dan, este parque era de uso mapuche para su sustento en la alimentación que eran los piñones, algunos tipos de hongo que se dan a esa altura sobre el nivel del mar, comestibles, hierbas medicinales, arbustos medicinales (E.H., comunicación personal, 28 de junio de 2015).

Por eso defendemos nuestro Pillán, porque decimos allá hay otro lawen y que también nos sirve y en el lago hay otra clase de remedio, y aquí a la mitad de nuestra comunidad que también hay remedio de lo que no hay arriba y de lo que no hay en el lago. (G.C., Comunicación personal, 12 de mayo de 2015).

Las plantas medicinales, no son curativas por sí mismas, según señala una vecina de la comunidad Carlos Antimilla, es importante el lugar de donde se extraen las plantas, indica que no es igual el lawen recogido en un huerto, que aquel que se produce en las faldas del volcán, pues este cuenta con una energía diferente que es curativa (notas de campo, 6 de setiembre de 2015), por eso es importante tener acceso a este lugar.

El conocimiento de los mapuche no se restringe al uso de determinadas plantas, sino que hay un énfasis en las formas cómo se realiza ese uso, de tal forma que la recolección, al igual que con el piñón, es un conocimiento presente en la cultura que arriesga perderse, por la dificultad de ser recreado:

El mapuche era tan sabio para eso, que pillaba una planta y no la sacaba toda y solo sacaba una o dos cogollos y no era cualquier planta sino una planta vigorosa una planta bonita, siempre el mapuche cuida o cuidaba lo que había (J.C., comunicación personal, 6 de setiembre de 2015). 
La naturaleza no sólo facilita alimento y medicina para los seres humanos, sino también para los animales domésticos. Otra práctica asociada a las faldas del Rucapillán, son las veranadas erradicadas por la CONAF en la década de los años 70. Al respecto, Aylwin (2008) señala que:

...la memoria de los ancianos mapuches no olvida hasta ahora como sus refugios en los faldeos del Rucapillán fueron quemadas por quienes administraron este PN, ni olvida los juicios seguidos en su contra por la tala de unos pocos árboles para la construcción de los refugios de veranada.

La veranada consistía en el alojamiento temporal en las faldas del volcán, donde se dan arbustos y frutos silvestres de alto valor nutritivo. Esta vegetación es apropiada para el engorde del ganado y la recolección para ser consumida en época de invierno. Dentro de las prácticas productivas, esta actividad es relevante, pues permite la rotación de los terrenos bajos desgastados en el invierno y que experimentan sequedad en la primavera y verano, mientras las partes altas imposibles de habitar durante el invierno, por las bajas temperaturas y la altura de la nieve, se mantienen verdosos en el período de veraneo cuando se va produciendo el deshielo.

La veranada normalmente es casi a mediados de primavera, de ahí en adelante hasta marzo, abril, por ahí. Entonces los animales los traían cuando ya empezaban a caer los piñones, traían sus animales y se iban ya a recolectar piñones, y no solamente recolectaban piñones, porque recolectaban hierbas medicinales, arbustos medicinales (E.H., comunicación personal, 28 de junio de 2015).

Las prácticas de la veranada y la piñonada confluyen en épocas, aunque es importante distinguirlas pues tienen objetivos y formas de relacionamiento con la naturaleza diferentes. Es importante destacar que para ambas actividades se utilizaron las rukas, tan presentes en la memoria de los miembros de las comunidades; estas constituyen un símbolo del despojo, a la vez son un símbolo de cohesión para la reivindicación de su identidad como mapuche.

El proceso de construcción de la ruka comunitaria hasta la convivencia con familias de diferentes lof, servían para la transmisión de conocimientos a las nuevas generaciones. Algunos de esos conocimientos se relacionan con: las formas de producción y recolección, las formas de comunicación con la naturaleza, el respeto y la hermandad con lo no-humano, concretado en las ceremonias religiosas, en las rogativas y los permisos, en la devolución y el pago. 
Las rukas destruidas por CONAF están presentes en los deseos de recuperación territorial, tanto de las personas que vivieron las veranadas, como de las generaciones que solo las conocen por las narraciones de sus padres, madres, abuelos y abuelas. Los escombros que quedan, luego de la destrucción, son un referente para mantenerlas en la memoria de las comunidades y mantener abierta la posibilidad de reconstruirlas.

La permanencia por semanas en las rukas y su existencia misma, era símbolo de arraigo territorial, de pertenencia y de vida comunitaria, es por ello que es puesta en valor por miembros de las diferentes comunidades.

\section{Conocer el territorio. Reto para las nuevas generaciones}

El conocimiento del territorio, las huellas para conectar diferentes lugares y espacios de interés cultural, es un conocimiento propio de las personas mayores que a los más jóvenes se les ha dificultado seguir. Las dinámicas y espacios para la transmisión de conocimientos se sustituyen por el espacio artificial construido desde Occidente, la escuela, de tal forma que el vínculo con la naturaleza se va perdiendo:

Por medio de la educación el mapuche pierde todo el valor que tenía, yo mismo no aprendí mucho sino que más he aprendido de la naturaleza, a cuidar la naturaleza eso no se lo enseñan en el colegio y eso sigue, sigue, sigue (J.C., comunicación personal, 6 de setiembre de 2015).

Los jóvenes reconocen la capacidad de los ancestros de conocer las huellas naturales, a la vez que ceden el poder/saber a la institucionalidad administradora del parque:

A.C.: Las veces que venía con mi papá caminábamos en la huella porque él ya se sabe, es muy fácil perderse porque son todos los lugares iguales. PM: pero yo lo que aprendí es que cualquier cosa, aquí hacia arriba, es que en cualquier lugar vas a encontrar con uno de esos banderines y tienes que seguir esos banderines y ahí sales a cualquiera de los dos lados. M.M.: y si no existieran esos banderines ¿con qué se guían? A.C.: bueno, mi papá se guía porque tiene años de andar por acá. (Diálogo entre jóvenes comunidad Juan Chañapi y comunidad Ramón Chincolef, comunicación personal, 4 de julio de 2015).

...nuestros abuelos avanzaban mucho, mucho para allá, iban atrás del volcán, de a caballo o de a pie, eran muy conocedores de toda la vida allá, porque arriba hay solo huellitas no más, la persona que sabe andar arriba encuentra esos caminos y el que no sabe se pierde, ellos tenían esa capacidad de explorar ellos (J.C., comunicación personal, 6 de setiembre de 2015).

ISSN: 1659-0066 
Según el mapa de "Sitios de significación cultural de las comunidades mapuchepehuenche de la comunidad Koñaripe-Alto" (Ciudadano \& Americanistici, S/F), existen al menos 60 sitios de interés socio-cultural que tienen relación, principalmente, con elementos de la naturaleza, tales como nacimientos de agua, cerros, zonas de pastoreo y recolección, bosques, lugares de reunión (como las rukas) y lugares ceremoniales. Estos sitios los identifican diferentes miembros de las comunidades, entre ellos, líderes de organizaciones y lonkos, de tal forma que recoge información relevante donde se evidencia la relación de la población mapuche con la naturaleza como eje central de su vida y su cosmovisión.

hay sitios sagrados, hay partes donde se paran los viejitos, nuestros abuelos, abuela tiene su parte a pedir las fuerzas, el newen como Mapuche, entonces como para cosechar piñón, por ejemplo, o animales porque de repente pueden resbalar o caer, que pueden torcerse los pies o quebrarse, entonces para que no les suceda eso... Nosotros como Mapuche queremos que esté, por ejemplo, que haya un bosque que esté vivo nuestra riqueza, porque eso nos da la vida a nosotros, la humedad viene de arriba para abajo la humedad, las aguas donde nacen, y si usted la explota arriba todo acá se seca, entonces proteger nuestros árboles, porque ellos vivieron un siglo...(G.C., comunicación personal, 12 de mayo de 2015).

Estos sitios de uso ancestral permiten reconocer una territorialidad propia de la cultura mapuche, un modo de habitar el mundo, es decir, desde las necesidades existenciales, formas de ser, estar, tener y hacer, en un territorio disputado con otros modos de vida, debido al despojo vivido y que se encuentran presentes en su cotidianidad. Según uno de los lonkos entrevistados, las faldas del Rucapillán les pertenecen desde los orígenes, porque su dueño mapuche nació ahí y surgió de la misma naturaleza del lugar:

...todos los alrededores le pertenecen a los Mapuches, CONAF llegó de último, [...] nosotros de donde vinimos, que somos de aquí. Porque la historia de Mapuche incluso (hace una pausa), existe aquí un Lonco mayor, antiguo que es Pallalafken y ese mandaba de Coñaripe hasta Challupén, mandaba todo este sector, y él era dueño de ese pillán, y la ascendencia de él nació de aquí mismo. Nació, era persona de piedra. Nació de piedra y luego se convirtió en persona, y ese Lonco es Caripán (G.C., comunicación personal, 12 de mayo de 2015).

Vemos aquí cómo converge en el territorio, lo simbólico y lo material, lo humano y lo no humano (una piedra hecha hombre). Por lo tanto, es importante retomarlo como concepto según la cosmovisión indígena: 
Para los pueblos indígenas la concepción tradicional de tierras va mucho más allá del sustrato material que permite la vida cotidiana de las personas, familias, comunidades o pueblos. Este concepto tradicionalmente de tierra está unido indisolublemente al concepto de territorio, y por tanto, incluye los elementos del entorno natural, tales como recursos naturales, bosques, aguas, suelos, subsuelos, cerros, quebradas, ríos, lagos, mar, flores, fauna, etc. [...] (Millaguir Neutopan, 2012).

Esta idea de territorio y su relación con el ser humano, es actualizada por las nuevas generaciones, quienes buscan recuperar su cultura, mediante el reconocimiento de los espacios sagrados y las prácticas de sus ancestros en el lugar. En esta búsqueda se resignifican los espacios, a través de nuevas experiencias y nuevos vínculos, muchas veces oníricos, donde se reconoce la importancia de los sueños en su cultura y a través de ellos se establece un nuevo vínculo con el territorio. Si bien existen sitios significativos para la colectividad, también hay sitios significativos por la experiencia individual en el territorio.

En la recuperación de prácticas transmitidas por los ancestros a los jóvenes, se potencia la relación armónica entre el ser humano y la naturaleza, por el aprendizaje de ceremonias y ritos donde se establece comunicación con lo nohumano. La juventud aprende a pedir permiso, pues sabe los riesgos de entrar a un lugar que tiene dueño, sin hacer un acto ceremonial de autorización. Así, el recorrido que se realiza con ellos al "Parque Nacional Villarrica", se lleva muday", para entregarle a la madre naturaleza, y se hace la rogativa para evitar los riesgos de perderse o tener un accidente.

Estas prácticas, transmitidas por los padres, contribuyen a la sustentabilidad del territorio en tanto hay un gran respeto por la naturaleza, la reconocen como ser viviente, como un igual.

\section{Conclusiones}

Los relatos de las personas entrevistadas, donde se referencian sus propias vivencias y las transmitidas oralmente por sus antepasados, son testimonio de la relación ancestral con el territorio que ocupa hoy el Parque Nacional Villarrica.

El intercambio de favores entre el ser humano, la naturaleza y los espíritus que habitan el mapu, es fundamental para mantener su equilibrio, tal como se desprende de las prácticas asociadas con la piñonada y la veranada.

\footnotetext{
${ }^{7}$ Muday es una bebida de trigo ligeramente fermentado.
} 
El bienestar de las personas también requiere del respeto hacia esos elementos, para el mantenimiento y el resguardo del alimento y el lawen; pero también para transferir el conocimiento a las nuevas generaciones.

A pesar de las regulaciones para el uso y acceso al territorio ocupado por el Parque, las comunidades han conservado una relación de respeto y reciprocidad con la naturaleza propia de su cosmovisión. Sin embargo, han experimentado cambios y adaptaciones de sus prácticas culturales, acompañadas de una fuerte resistencia y lucha constante por recuperar el territorio frente al Estado chileno.

Se identifican diferentes territorialidades entre las comunidades del sector, según las vinculaciones heterogéneas establecidas con el entorno. Confluyen, además, formas colectivas e individuales de vivir el espacio, signado por el historial de despojo y adaptación a las nuevas condiciones de vida y el alejamiento de la naturaleza. 


\section{BIBLIOGRAFÍA}

Aylwin, J. (2008). ¿De quién es el Parque Nacional Villarrica? Recuperado de www.lanacion.cl/prontus_noticias_v2/site/artic/20081206/pags/200812062137 05.html

Ciudadano, O., \& Americanistici, C. S. (S/F). Sitios de significación cultural de las comunidades mapuche-pehuenche de la comunidad Koñaripe-Alto. Recuperado de http://www.observatorio.cl/sites/default/files/biblioteca/anexo_2.6_cartografia _conaripe_pocura_traitarico.

Correa, M., \& Mella, E. (2010). Las razones del illkun/enojo. Memoria, despojo y criminalización en el territorio mapuche de Malleco. Santiago, Chile: LOM.

Corporación Nacional Forestal. (2006). Plan de Manejo Parque Nacional Villarrica. Temucho, Chile.

Corporación Nacional Forestal. (2013). Plan de Manejo Parque Nacional Villarrica. Segunda edición ed. Temucho, Chile.

Millaguir, D. (2012). Panguipulli, historia y territorio. 1850-1946. Chile.

Millalén, J. (2006). La sociedad mapuche prehispánica: Kimú, arqueología y etnohistoria. S. Marimán, J. Caniuqueo, \& Millalén.... (Eds.), ii...Escucha, winka...! Santiago, Chile: LOM.

Roma, I. (2012). Antecedentes generales sobre la práctica de recolección de piñones en el Lof Antimilla, vecinos del Parque Nacional Villarrica, en la localidad Coñaripe. Inédito. 
Revista Herencia, Vol. 31 (1), enero-junio, 2018. 